Dossiê

Dramaturgia Musical

Ensino e prática de música com programação de software

Alexandre G. Q. Rangel

Revista do Laboratório de Dramaturgia - LADI - UnB - V. 2 e 3, Ano 1 


\title{
Ensino e prática de música com programação de software
}

\author{
Alexandre G. Q. Rangel ${ }^{1}$ \\ Artista Multimídia e pesquisador
}

Resumo: Este artigo relata a execução do objeto de pesquisa de Doutorado em Artes, um grupo de seis oficinas de criação multissensorial com programação de software Sonic Pi. O foco das oficinas, cada uma com um músico convidado, foi a produção musical e a iniciação à programação de software criativo.

Palavras-Chave: Multissensorialidade, Sonic Pi, Produção musical

Abstract: This article details the execution of the research object of a Doctorate in Arts, a group of six workshops on multisensorial creation with Sonic Pi software development. The focus of the classes, each with an invited musician, was musical production and creative software development initiation.

Keywords: Multi-sensoriality, Sonic Pi, Musical Production

As pesquisas realizadas entre junho e novembro de 2016 são o principal objeto de estudo do meu doutorado em artes em andamento pela Universidade de Brasília (UnB IdA). O foco das oficinas é a realização de uma pesquisa sobre as possibilidades criativas e educacionais da prática de programação de software para criação sonora. O estudo visa mapear a abrangência da prática artística e as potencialidades do ensino de criação musical por meio de desenvolvimento de software para computadores.

Foram realizados 6 módulos de oficinas e performances audiovisuais. Cada módulo contou com a participação de um músico convidado, a fim de propiciar um diálogo e interação entre música com instrumentos tradicionais e a música com programação de software. Esses mesmos músicos participam de análises sobre o material criado nas oficinas, permitindo um mapeamento para multiplicação das experiências por outros grupos. Serão criados, durante o projeto, relatório de pesquisa, apostila didática e videoaulas para acompanhar o processo de aprendizado nas oficinas e em desdobramentos do projeto. $\mathrm{O}$ projeto vislumbra a mistura e o crescimento mútuo das Ciências Humanas e Exatas, uma vez que as práticas desenvolvidas e os profissionais envolvidos são multidisciplinares (desenvolvimento de software, música e artes visuais). O computador já intermedia o ensino e, principalmente, o consumo de música. O projeto prevê uma importante mudança de paradigma, transformando a postura de consumo em postura de investigação, exploração e criação. Esta mudança também abre portas para uma ampliação do escopo ferramental de estudantes de Ciências Humanas e Exatas, trabalhando, ao mesmo tempo, capacitação para as Artes e para Tecnologias da Informação. A música será utilizada como foco principal das atividades, que caminham no projeto em confluência com as artes visuais,

1 Realiza atualmente estudos doutorais no PPG-Arte Universidade de Brasilia. V. http://www.quasecinema.org . 
com resultado de expressão audiovisual multimídia em novas mídias.
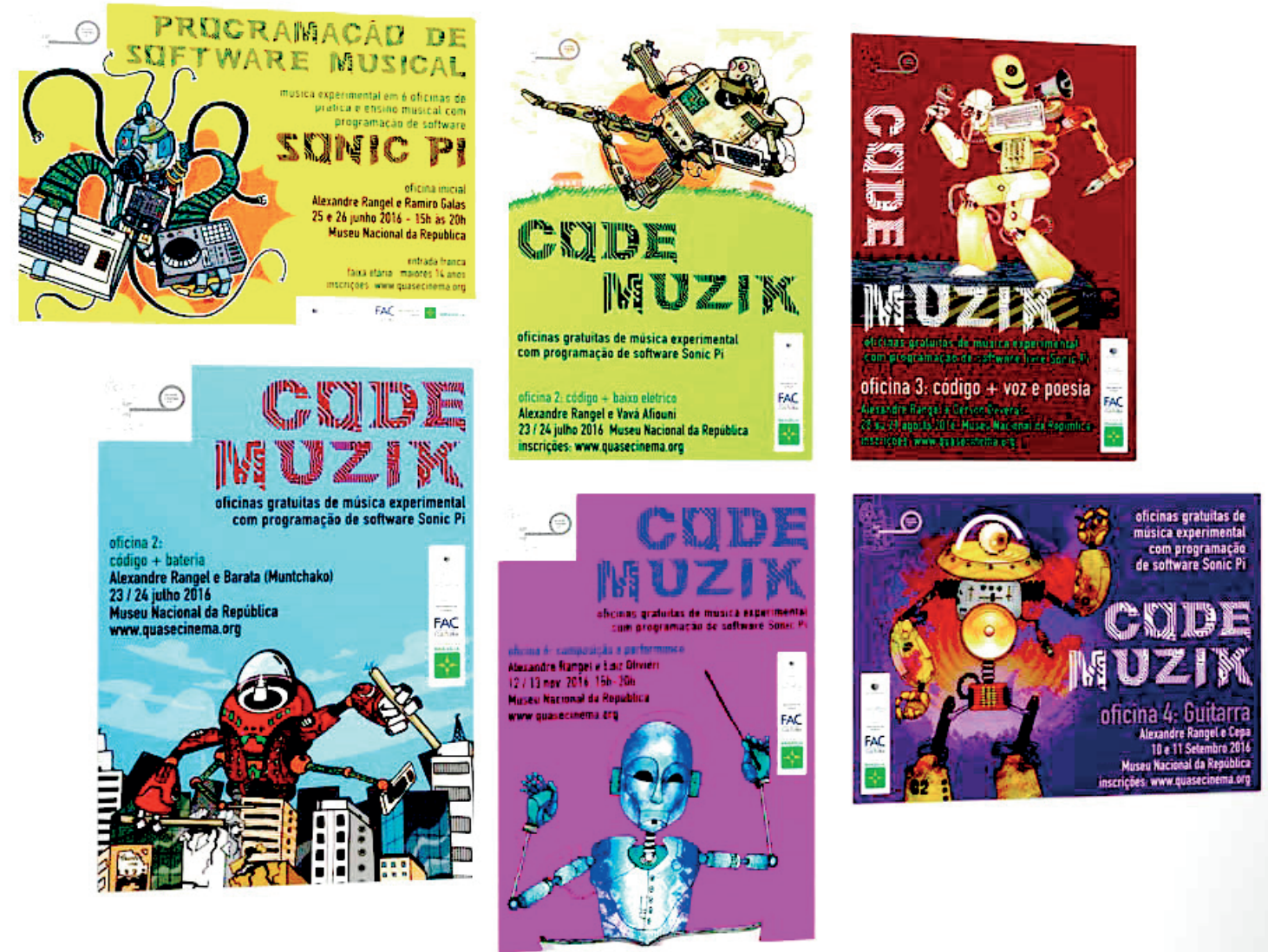

Imagem 1: Cartazes de divulgação das oficinas do projeto.

As práticas similares já realizadas pelo proponente (oficinas, performances artísticas, mestrado em arte-educação) indicam um grande valor do processo lúdico da criação musical no ensino de programação e vice versa, uma vez que os conceitos e processos computacionais tradicionais podem dar inesperados e surpreendentes frutos musicais. A proposta se baseia completamente em uso de software livre, possibilitando a multiplicação dos recursos criativos com o menor ônus financeiro possível:

- Criação de material didático, visando a multiplicação das ações de capacitação.

- Realização de oficinas.

- Análise do material criado nas oficinas por profissionais de música do DF.

- Realização de performances.

- Análise do material apresentado nas performances.

- Avaliação do ferramental proposto como ferramentas educacionais multidisciplinares.

As oficinas, oferecidas gratuitamente, foram patrocinadas pelo primeiro edital de "Pesquisa Musical" do Fundo de Apoio à Cultura (FAC), da Secretaria de Cultura do Governo de Brasília (2016). O projeto também contou com a parceria do Museu Nacional do Conjunto Cultural da República de Brasília apresentou o projeto, contribuindo com apoio técnico, disponibilização dos espaços físicos das oficinas (Auditório Kalunga 
e Anexo do Museu).

\section{Oficina 1, com Ramiro Galas}

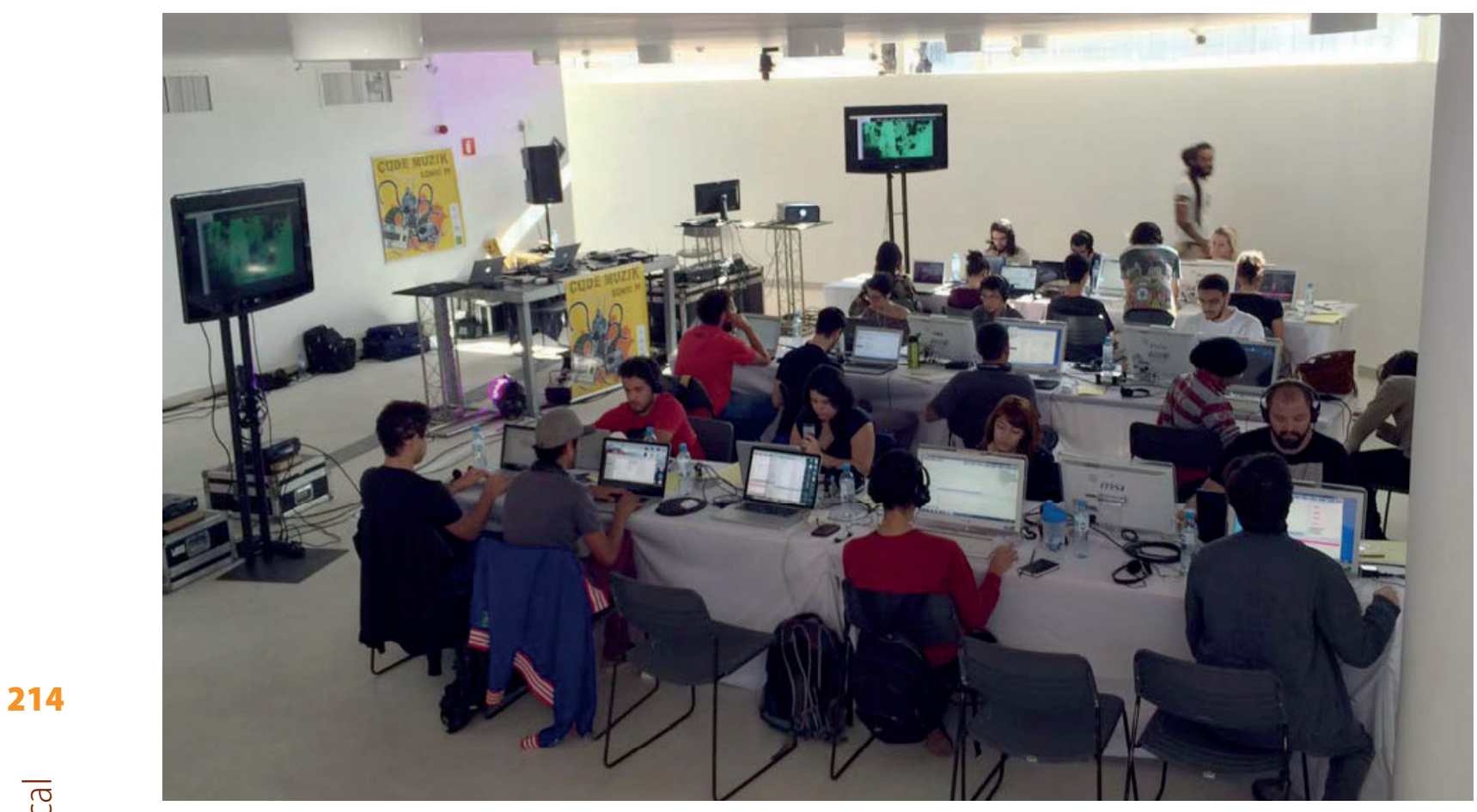

Imagem 2: Oficina CODE MUZIK 1 (junho, 2016) no Anexo do Museu Nacional de Brasília.

Um das maiores descobertas/invenções da primeira oficina foi de como programar um sequenciador de bateria eletrônica diretamente e somente com o software Sonic Pi. Esta técnica se mostrou de extrema facilidade e utilidade para as criações de todas as outras oficinas já realizadas durante esta pesquisa.

\section{Oficina 2, com Vavá Afiouni}

Observou-se a necessidade de mais ensaios com os músicos, antes da realização das oficinas. Produção de software e estudo de metodologia de transcrição de melodias para a linguagem do Sonic Pi.

No exemplo de código a seguir, composto durante a oficina, a linha de baixa da música "Billie Jean²", de Michael Jackson (1982). A forma de colocar as notas na programação seguem o padrão de sequenciador desenvolvido na oficina 1 (em negrito no exemplo abaixo).

live_loop :notasLongas do use_synth :beep

with_fx :flanger, phase: 1 do

play :G4, amp: $\operatorname{ring}(1,0,0,0,0,0,0,0,0,0,0,0,0,0,0,0)[y]$

2 https://en.wikipedia.org/wiki/Billie_Jean 
play :A4, amp: ring $(0,0,0,1,0,0,0,0,0,0,0,0,0,0,0,0)[y]$

play :Bb4, amp: $\operatorname{ring}(0,0,0,0,0,0,0,0,1,0,0,0,0,0,0,0)[y]$

play :A4, amp: $\operatorname{ring}(0,0,0,0,0,0,0,0,0,0,0,1,0,0,0,0)[y]$

play chord(:G4,:m7), release: 6 ,

amp: $\operatorname{ring}(1,0,0,0,0,0,0,0,1,0,0,0,0,0,0,0)[y] * 0.5$ if one_in $(2)$

end

sleep 1

$y=y+1$

end

\section{Oficina 3, com Gérson Deveras}

Gérson falou sobre o processo de musicalização da palavra e da colocação da palavra falada e cantada em cima de batidas musicais. Os participantes da oficina foram incentivados a criar dois tipos de materiais: bases musicais com ritmos brasileiros para uso em posterior improvisação vocal e textos para leitura, gravação e posterior manipulação experimental com a metodologia de criação de software. Foi explorada a experimentação e produção de software para manipulação de vozes gravadas, por meio do uso de filtros e recortes com o sistema de samples (amostras musicais, trechos de áudio gravados) do Sonic Pi.

Nessa oficina ficou muito claro o potencial de contribuição entre homem e máquina. Graças à fluente criatividade, flexibilidade e controle vocal do artista convidado. Nos momentos finais da oficina, quando é estimulada a improvisação e a mesclagem de ideias, os participantes puderam executar suas composições em software enquanto o cantor encaixava sobre as batidas letras de canções e poesias.

\section{Oficina 4, com Cepa}

A oficina com o guitarrista Cepa (Sérgio Azevedo) teve como foco o uso do Sonic Pi como um processador de efeitos sonoros em tempo real. Isto é, criamos composições/ softwares capazes de capturar o áudio proveniente dos instrumentos (guitarras) e aplicar efeitos imediatamente, tal como pedais de guitarra. A comparação com pedais de guitarra foi inevitável, e constatamos a flexibilidade e um grande potencial criativo com sistema, uma vez que pedais de guitarra costumam fazer um só efeito e com poucos parâmetros configuráveis. Trabalhando os efeitos usando o Sonic Pi, pudemos atribuir variáveis aleatórias, previsíveis ou não, às configurações, tornando os efeitos vivos e dinâmicos.

Tivemos que nos acostumar com as possibilidades dos efeitos em tempo real, especialmente as possibilidade de controle intuito de efeitos de eco e retorno (feedback).

\section{Oficina 5, com Barata}

Oficina com a participação do baterista Rodrigo Tavares (Barata). Barata, além de 
baterista do grupo de rock Muntchako, tem carreira como DJ do coletivo Criolina, muito ativo na cena cultural de Brasília. Um dos maiores desafios foi a sincronização entre os softwares desenvolvidos pelos participantes da oficina e o músico convidado, com sua bateria "real".

A grande "descoberta" deste módulo foi a possibilidade do uso, por meio do Sonic $\mathrm{Pi}$, de poliritmos, graças à implementação simples e objetiva de comandos de criação de ritmos euclidianos. Essa técnica é extremamente intuitiva para a exploração de ritmos de forma improvisada.

\section{Oficina 6, com Luiz Oliviéri}

A oficina com o compositor Luiz Oliviéri teve o intuito de reunir todo o conhecimento e técnicas desenvolvidas nas outras oficinas, objetivando práticas de composição e performance musicais. Olivéri trouxe para os participantes seus conhecimentos teóricos e práticos de arranjamento, traduzindo os preceitos tradicionais para o terreno da programação de software. Aprendemos como desmembrar uma composição em várias partes, tais como introdução, desenvolvimento, pontes, e loops principais.

\section{Equipamentos utilizados nas oficinas}

Foram locados os seguintes equipamentos para a realização das oficinas:

- Projeção de vídeo: 2 projetores de vídeo de 7.000 lumens e 1 projetor de vídeo de curta distância de 3.000 lumens.

- Sonorização: mesa de mixagem de áudio de 24 canais, mesa de mixagem e gravação de áudio multipistas de 8 canais, cabeamentos de áudio para os participantes e microfones.

- Computadores (dez) com sistema operacional Windows para os participantes ${ }^{3}$.

\section{Experiências dos participantes das oficinas}

Onde acontece a arte? São as performances e composições realizadas? Sim, mas começa antes dos produtos e vai além dos encontros de fim de semana realizados. O processo de capacitação em criação de software, aliado ao desprendimento da criação musical por pessoas sem formação formal, possibilita uma atuação efetiva no campo expandido da arte (Krauss). A quebra de paradigmas que (proposta) acontece perante nossos olhos acontece em sintonia conceitual com a provocação intelectual e a liberdade de formatos e suportes que caracteriza a arte contemporânea. A proposta do projeto mostra a sua tangência com o trabalho de Joseph Beuys, que pregava que qualquer um pode ser um artista - aqui que se mostrou aberto às ideias pôde ser tornar - efetiva e duradouramente - um

3 O Sonic Pi pode ser utilizado em computadores com os principais sistemas operacionais (Linux, Mac OS e Windows). 
músico e um desenvolvedor de software.

Alguns participantes do público se destacaram na realização das propostas das oficinas. Fernando Mazoni, percussionista do grupo musical performático Patubatê, ao participar da oficina com o artista Gérson Deveras, criou batidas com ritmos brasileiros no sistema Sonic Pi. Encontram-se disponíveis no material didático online os ritmos de Côco e Maracatu.

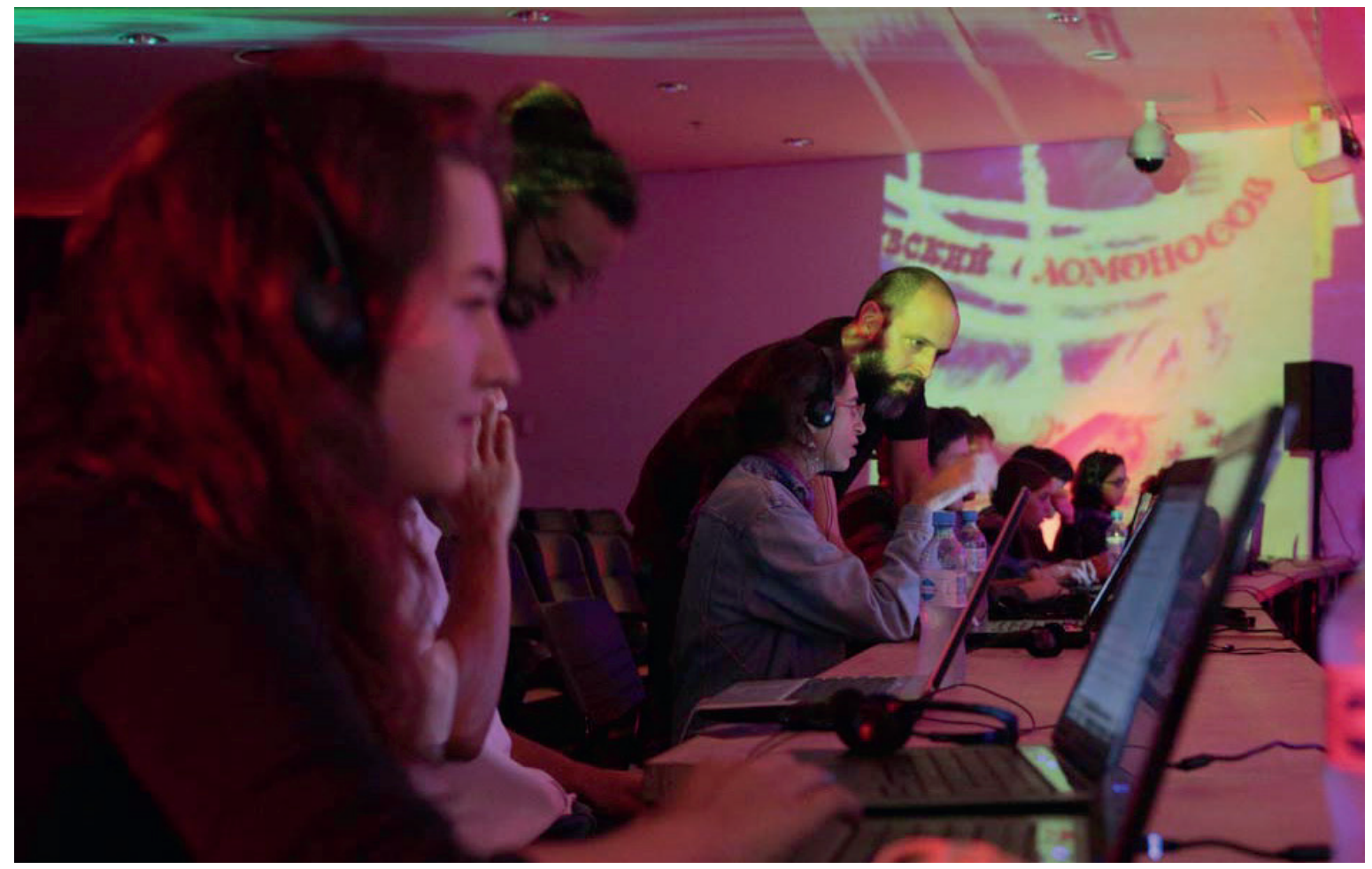

Imagem 3: Oficina 6 (novembro, 2016) no Auditório Kalunga do Museu Nacional de Brasília.

O que nós aprendemos com os sistemas desenvolvidos e processos criados? A exploração dos sistemas individualmente, dos sistemas em grupo e dos sistemas juntamente com os músicos convidados levou à uma série de conclusões - e inúmeras outras indagações técnicas e criativas, a serem desenvolvidas no curso dos estudos de doutorado iniciados em 2016. Foi enfatizada a liberdade para o grupo construir partículas musicais e performáticas, com a voz e com instrumentos criados com software. Já chegamos à sofisticação de desenvolvimento de software para podermos escolher escalas e notas musicais com movimentos corporais (via câmera de vídeo tipo webcam) ou movimentos de mouse.

\section{Material didático}

Faz parte da proposta de pesquisa e desenvolvimento do doutorado em andamento a criação de material didático online sobre a prática artística com a técnica de live coding. Uma apostila digital sobre, em construção, já está disponível no site quasecinema.org ${ }^{4}$

4 http://www.quasecinema.org/sonicpi.html 
Mais do que uma tradução do manual original do Sonic Pi, o material explora detalhadamente todos os instrumentos virtuais disponíveis no software e apresenta exemplos de código que podem ser executados imediatamente no Sonic $\mathrm{Pi}$, incentivando a compreensão e a experimentação por meio da combinação de vários pedaços de código e modificação dos valores atribuídos a variáveis.

O material didático online também contam com registros em vídeo das seis oficinas. Duas matérias da Rede Globo de televisão também estão vinculadas na página do projeto. Uma das matérias foi gravada na oficina número dois, no Museu Nacional.

\section{Softwares desenvolvidos durante o projeto PiControl}

A fim de tornar as performances com o Sonic Pi mais expressivas e tornar as composições mais interessantes, desenvolvi um software para modificar partes dos códigos musicais com controladores MIDI. Controladores MIDI são equipamentos eletrônicos que permitem a interação com softwares de criação musical. Eles podem ter a forma de teclados de piano, baterias eletrônicas com pads sensíveis à pressão e/ou combinações de knobs (botões de rotação) e sliders (botões deslizantes verticais ou horizontais).

Para o funcionamento deste software, concebi o seguinte caminho, "ingênuo, porém eficiente" (Sam Aaron):

a) Um controlador MIDI é conectado via cabo USB a um computador rodando sistema operacional Linux, Mac OS ou Windows.

b) O código desenvolvido no Processing (Java) lê as informações enviadas pelo controlador MIDI.

c) O parâmetro do controlador sendo modificado é gravado em um arquivo de texto (TXT).

d) O código desenvolvido no Sonic Pi (Ruby) lê cada arquivo de texto e vincula o valor lido à uma variável musical, definida pelo músico.

\section{Projeto Weekly Beats 2016}

O projeto Weekly Beats é um desafio de criação musical online. O objetivo de cada participante é criar uma música por semana e disponibiliza-la para acesso pela Internet. Não existe premiação. O intuito da participação no desafio é o crescimento pessoal e a troca de informações com outros artistas.

O projeto acontece de dois em dois anos. Em 2014 participei com a proposta de criar uma música e um vídeo por semana. Missão cumprida: 52 obras de vídeo arte / música visual criadas, em um dos anos que mais cresci como artista em toda a minha carreira. Em 2016, como atividade de produção e pesquisa alinhada com essa pesquisa de doutorado, propus a criação de uma obra por semana utilizando somente a técnica de live coding - com o software Sonic Pi.

A atenção agora se voltou às limitações criativas escolhidas voluntariamente para aumentar o potencial criativo das composições - como John Cage, ao utilizar o I Ching como definição de elementos não previstos. 


\section{Computador como instrumento: conexão com a simplicidade}

Meu primeiro contato com sistemas de programação de computadores foi em 1986, quando eu tinha 12 anos de idade. A lógica que aprendi na época, o fluxo de um software e os comandos básicos de programação são a base de tudo que desenvolvo nessa área desde então. $\mathrm{Na}$ época o aprendizado era feito com a linguagem $\mathrm{Basic}^{5}$, disponível na maioria dos computadores pessoais da época, como o Apple Ile que eu possuía. A minha trajetória de capacitação de uso de linguagens de computador acabou sendo um bom estudo de caso, uma vez que já se passaram 30 anos do meu contato inicial com essa área e ainda continuo estudando e desenvolvendo a prática de desenvolvimento (criativo) de software. Durante esses anos, me apaixonei e me aprofundei nos ambientes de programação Macromedia Director $^{6}$ (1994), Blender 3D Game Engine ${ }^{7}$ (2004) e Processing ${ }^{8}$ (2007). Todos esses sistemas de desenvolvimento são foram criados e direcionados para o uso por profissionais de campos criativos (áudio, vídeo, $3 \mathrm{D}$, interatividade), sem o pré-requisito de uma formação acadêmica em informática. Mesmo sendo voltados, principalmente, para o público vindo das ciências humanas, nenhum desses ambientes se compara com a simplicidade inicial do Sonic $\mathrm{Pi}^{9}$, criado para ser usados, principalmente, por crianças da faixa etária em torno dos 8 anos. A espinha dorsal da pesquisa é o software Sonic $\mathrm{Pi}-$ uma ferramenta para criação e performance musical baseada em código de software. Ou seja deve-se escrever linhas de código (um programa) para criar ritmos, notas e/ou texturas musicais. O Sonic Pi pode ser compreendido como um ambiente de criação sonora (e também visual) baseado na linguagem de programação Ruby ${ }^{10}$. Ou seja, se escreve um dialeto de Ruby durante o processo criativo. O Sonic Pi foi desenvolvido por Sam Aaron, professor da Universidade de Cambridge. A primeira versão do software contou com o patrocínio da Fundação Raspberry $\mathrm{Pi}^{11}$, que produz computadores miniaturas para salas de aula e projetos de arte interativa e engenharia de fundo de quintal (hacker). Hoje, como vemos, o Sonic Pi se apresenta como programa ideal para iniciação de aprendizado de desenvolvimento de software criativo multimídia.

5 https://pt.wikipedia.org/wiki/BASIC

6 https://en.wikipedia.org/wiki/Adobe_Director

7 http://www.blender.org

8 http://www.processing.org

9 http://sonic-pi.net

10 https://pt.wikipedia.org/wiki/Ruby_(linguagem_de_programação)

11 http://www.raspberrypi.org 